\title{
Pattern of Magnetic Resonance Imaging Findings in Low Back Pain
}

\author{
Authors \\ Santhosh Kumar Aravapalli ${ }^{1}$, Aditya Abhishek .K ${ }^{1}$, Nithin Reddy.D ${ }^{1}$, Raju Ragidi ${ }^{1}$ \\ Dr H.R.Nagrale ${ }^{2}$, Dr Veeraswamy ${ }^{3}$ \\ ${ }^{1}$ PG Radio-Diagnosis, ${ }^{2} \mathrm{HOD},{ }^{3}$ Professor in Department of Radio-Diagnosis, Mamata General \& Super \\ Specialty Hospital, Khammam, Telangana \\ Corresponding Author
}

Dr Santhosh Kumar Aravapalli

Post Graduate Radio-Diagnosis, MGH, Khammam, Pin: 507002

Email: mbbs.santhosh@gmail.com

\begin{abstract}
Introduction- Low back pain (LBP) is the one of the most prevalent complaints among the people. India has an increasing number of patients who present with LBP. The presentation, detection and characterization of lesions in LBP are sometimes clinically indistinguishable, necessitating evaluation by MRI.

Aim- The purpose of this study was to undertake a critical review of the potential role of magnetic resonance imaging in evaluation of low back pain (LBP) and to describe various MRI findings.

Methodology- The study was conducted at the Radiology and Imaging department of the Mamata medical college, khammam, india. It was a cross-sectional study whose subjects were adult patients with LBP referred for lumbar spine MRI. A total of 151 patients with LBP, with no contraindications to MRI underwent MRI from july 2015 to december 2015 were studied. Frequency tables were generated for categorical variables.

Results-The most common site for degenerative findings was L4/L5 followed by L5/S1. Nerve root compression was the most common complication.

Conclusion: This study established the use of MRI as the radiological investigation for detection of low back pain. It was concluded that LDD is common in the lower lumbar regions.

Keywords: Magnetic Resonance Imaging, Patients, Low Back Pain, Disc bulge

\section{INTRODUCTION}

Low back pain belongs to one of the most common sufferings observed in mankind and can lead to serious limitation of activity. ${ }^{1}$ Low back pain has been described as "an illness in search of a disease" 2 The sequelae of disc degeneration are among the leading causes of functional incapacitancy in both sexes and are a common source of chronic disability

in the working years. There is high prevalence of degenerative changes in asymptomatic individuals. Our study involves the degenerative changes in symptomatic individuals. The role of mri imaging is to provide accurate morphological information and influence therapeutic decision making.

MRI is also useful in planning surgical management of patients with sciatica attributable to lumbar disc herniation $^{3}$, in determining vertebral end-plate
\end{abstract}


changes and facet joint effusions when selecting patients for spinal fusion. ${ }^{3}$

Hence, MRI is the emerging radiological diagnostic tool in the management of low back pain.

\section{MATERIALS AND METHODS}

\section{Study Site}

This study was carried out at mamata general and super speciality hospitals, khammam, telangana

\section{Study Design}

This study was a hospital-based cross-sectional study conducted from july 2015 to December 2015 .

\section{Study Population}

The study included patients with LBP with or without radiculopathy who were referred for lumbar spine MRI from July 2015 to December 2015.

\section{Inclusion Criteria}

All patients with LBP with or without radiculopathy as the primary and only diagnosis or in association with other pre-existing conditions referred for MRI.

\section{Exclusion Criteria}

All the cases with infections and tumours were excluded from the study and contraindications to MRI such as metallic implants in the lumbar spine, pacemakers, claustrophobia and Pregnancy were considered in the exclusion criteria.

\section{MRI Imaging Protocol}

MR examination of the lumbar spine at presentation was performed with 1.5 tesla MR imager using the spine phased array coils. The scans consisted of sagittal and axial T1-weighted and T2-weighted turbo spin echo and STIR images.

\section{RESULTS}

The Most Common MRI Pattern in Patients with Low Back Pain:

Lumbar disc degeneration (LDD) was common $(81.45 \%)$ in LBP patients studied. The common lumbar spine degenerative findings in patients with low back pain were disc bulges 108 (71.52\%), herniations $87(57.61 \%)$, anterior osteophytes 57 (37.74\%), endplate (Nordic) changes 34 (22.51\%), ligamentum flavum hypertrophy $11(7.28 \%)$ facet joint arthrosis 17 (11.25\%), and spondylolisthesis 3 (1.98\%) shown in Table 1 below.

Table 1: A table showing lumbar spine degenerative changes

\begin{tabular}{|l|c|}
\hline VARIABLE & FREQUENCY (\%) \\
\hline Disc bulge & $108(71.52)$ \\
\hline Herniations & $87(57.61)$ \\
\hline Anterior osteophytes & $57(37.74)$ \\
\hline $\begin{array}{l}\text { Endplate (modic) changes } \\
\text { Ligamentum flavum } \\
\text { hypertrophy }\end{array}$ & $34(22.51)$ \\
\hline Facet joint arthrosis & $11(7.28)$ \\
\hline Spondylolisthesis & $3(1.98)$ \\
\hline
\end{tabular}

Lumbar degenerative changes according to age wise distribution and sex wise distribution are shown in following figures.

Age wise distribution showing cases of 3rd decade are $32(21.19 \%)$, cases of $4^{\text {th }}$ decade are 57 $(37.74 \%)$ and cases in $5^{\text {th }}$ decade are $29(19.20 \%)$.
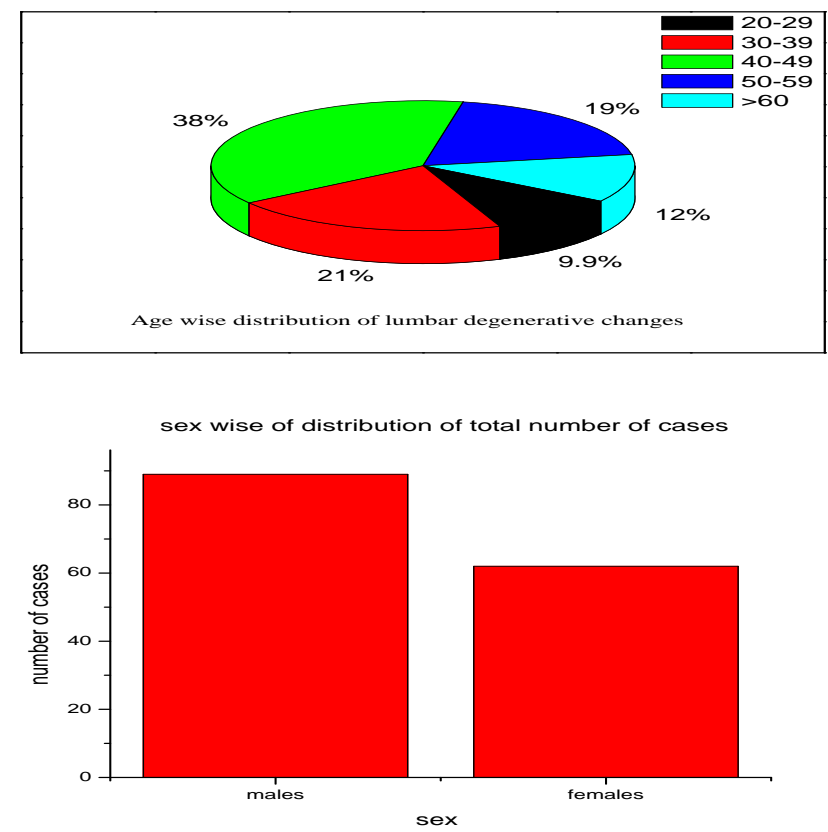

Bar diagram shows sex wise distribution of total number of cases of which male to female ratio of lumbar degenerative changes are 90: 61 (59.60\%:40.39\%). 
The Common Disc Contour Abnormalities in Patients with Low Back Pain

Patients with degenerative disc disease had the following disc contour abnormalities. Bulges 108 $(71.52 \%)$ and herniations were further reported as broad based herniations $54(62.06 \%)$, extrusions 4 (4.59\%) and the protrusions 29 (33.33\%).

\section{Lumbar Disc Degeneration \\ Bulges}

The most common site for bulges was L4/L5 with 95 cases (87.96\%). The most common complication of bulges was impingement of exiting nerve roots $41(47.12 \%)$ as shown in Table 2

Table 2: A table showing bulges

\begin{tabular}{|l|c|}
\hline VARIABLES & FREQUENCY(\%) \\
\hline Bulges & $108(71.52)$ \\
\hline Site of lesion & $\mathrm{N}=108$ \\
\hline L1-L2 & $1(0.92)$ \\
\hline L2-L3 & $12(11.11)$ \\
\hline L3-L4 & $26(24.07)$ \\
\hline L4-L5 & $95(87.96)$ \\
\hline L5-S1 & $79(73.14)$ \\
\hline COMPLICATIONS & $\mathrm{N}=87$ \\
\hline Mild thecal sac indentation & $12(13.79)$ \\
\hline Impingement of exiting nerve root & $41(47.12)$ \\
\hline $\begin{array}{l}\text { Impingement on nerves and cauda } \\
\text { equina }\end{array}$ & $7(8.04)$ \\
\hline Compression of exiting nerve root & $25(28.73)$ \\
\hline
\end{tabular}

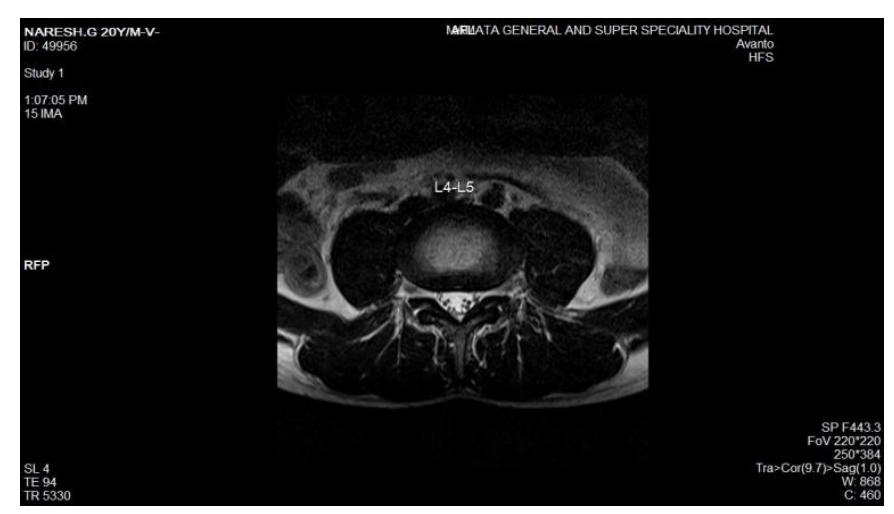

Fig.1. Axial mri showing diffuse disc bulge

\section{Herniations}

The most common site for herniations was L4/L5 52 $(59.77 \%)$. The most common complication of herniations was compression of exiting nerve roots and cauda equina $29(70.73 \%)$ as shown in Table 3

\begin{tabular}{|l|c|}
\hline VARIABLE & FREQUENCY(\%) \\
\hline Type of herniation & $\mathrm{N}=87(57.61)$ \\
\hline Broad based herniations & $54(62.06)$ \\
\hline Extrusions & $4(4.59)$ \\
\hline Protrusions & $29(33.33)$ \\
\hline SITE OF LESION & $\mathrm{N}=87$ \\
\hline L1-L2 & $5(3.44)$ \\
\hline L2-L3 & $8(5.74)$ \\
\hline L3-L4 & $52(59.77)$ \\
\hline L4-L5 & $19(21.83)$ \\
\hline L5-S1 & $\mathrm{N}=41$ \\
\hline COMPLICATIONS & $6(2.44)$ \\
\hline Mild thecal sac indentation & $3(7.63)$ \\
\hline $\begin{array}{l}\text { Impingement of exiting } \\
\text { nerve root }\end{array}$ & $29(70.73)$ \\
\hline $\begin{array}{l}\text { Impingement on nerves and } \\
\text { cauda equine }\end{array}$ & $2(4.88)$ \\
\hline $\begin{array}{l}\text { Compression of exiting } \\
\text { nerve root }\end{array}$ & \\
\hline \begin{tabular}{l} 
Spinal canal stenosis \\
\hline
\end{tabular} & \\
\hline
\end{tabular}

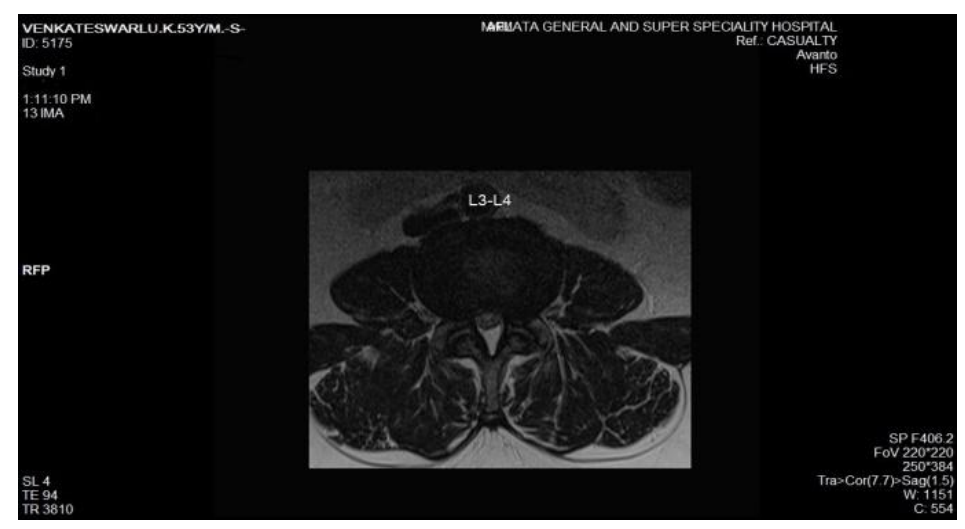

Fig.2. Axial mri image of lumbar spine showing bilateral protrusion of disc

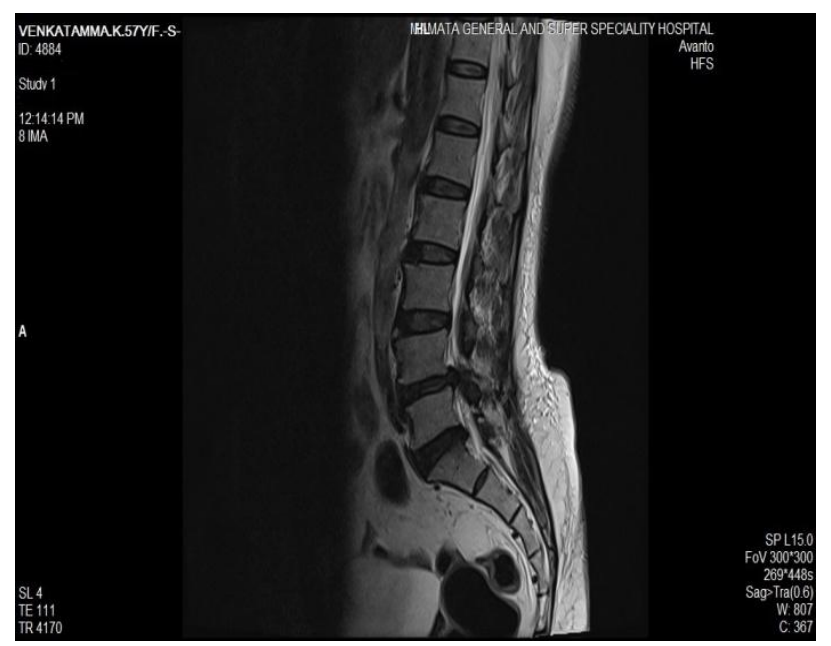

Fig.3. Sagittal mri image of lumbar spine showing extrusion of L4-L5 disc 


\section{Anterior osteophytes}

Anterior osteophytes most commonly seen at the level of L4-L5 24 (42.85)

Table 4: Table showing anterior osteophytes

\begin{tabular}{|l|c|}
\hline VARIABLE & FREQUENCY(\%) \\
\hline Anterior osteophytes & $53(35.09)$ \\
\hline Site of lesion & $\mathrm{N}=53$ \\
\hline L1-L2 & $11(20.75)$ \\
\hline L2-L3 & $14(26.41)$ \\
\hline L3-L4 & $19(35.84)$ \\
\hline L4-L5 & $24(42.85)$ \\
\hline L5-S1 & $20(37.73)$ \\
\hline
\end{tabular}

\section{End plate changes}

Table 5: Table showing end plate (modic changes)

\begin{tabular}{|l|c|}
\hline VARIABLE & FREQUENCY \\
\hline End plate changes & $34(22.51)$ \\
\hline SITE OF LESION & \\
\hline L1-L2 & $5(14.7)$ \\
\hline L2-L3 & $2(5.8)$ \\
\hline L3-L4 & $6(17.6)$ \\
\hline L4-L5 & $12(35.2)$ \\
\hline L5-S1 & $9(26.4)$ \\
\hline
\end{tabular}

\section{Ligamentum flavum hypertrophy}

Table 6: Table showing ligamentum flavum hypertrophy

\begin{tabular}{|l|c|}
\hline VARIABLE & FREQUENCY \\
\hline $\begin{array}{l}\text { Ligamentum flavum } \\
\text { hypertrophy }\end{array}$ & $11(7.28 \%)$ \\
\hline SITE OF LESION & \\
\hline L1-L2 & $1(9.0)$ \\
\hline L2-L3 & $0(0)$ \\
\hline L3-L4 & $2(18.1)$ \\
\hline L4-L5 & $5(45.4)$ \\
\hline L5-S1 & $3(27.2)$ \\
\hline
\end{tabular}

\section{Facet joint arthrosis}

The most common site for facet joint arthrosis was L4-L5 4(23.5)

Table 7: Table showing facet joint arthrosis

\begin{tabular}{|l|c|}
\hline VARIABLE & FREQUENCY \\
\hline Facet joint arthrosis & 17 \\
\hline
\end{tabular}

\begin{tabular}{|l|c|}
\hline Unilateral & $13(76.47)$ \\
\hline Bilateral & $4(23.52)$ \\
\hline SITE OF LESION & \\
\hline L1-L2 & $2(11.7)$ \\
\hline L2-L3 & $1(5.8)$ \\
\hline L3-L4 & $3(17.6)$ \\
\hline L4-L5 & $4(23.5)$ \\
\hline L5-S1 & $7(41.1)$ \\
\hline
\end{tabular}

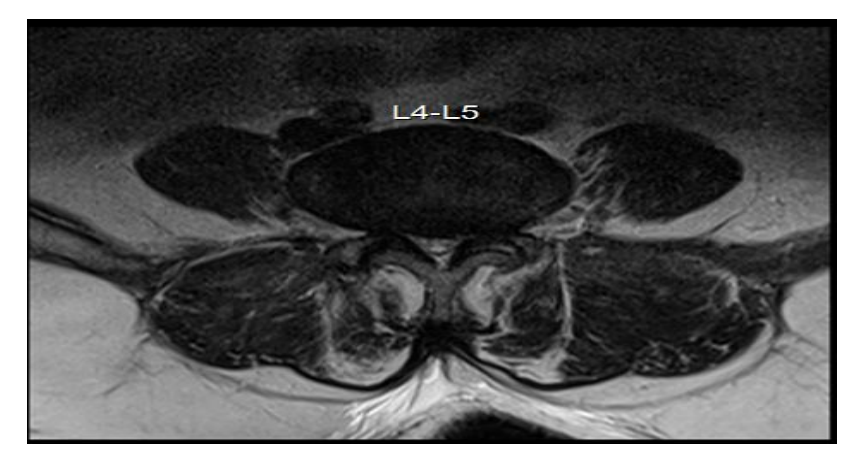

Fig.4. Axial image of lumbar spine showing right facet joint arthrosis

\section{Spondylolisthesis:}

Table 8: Table showing spondylolisthesis

\begin{tabular}{|l|c|}
\hline VARIABLE & FREQUENCY \\
\hline Spondylolisthesis & $3(1.98)$ \\
\hline L1 over L2 & $0(0)$ \\
\hline L2 over L3 & $0(0)$ \\
\hline L3 over L4 & $0(0)$ \\
\hline L4 over L5 & $1(33.33)$ \\
\hline L5 over S1 & $2(66.66)$ \\
\hline
\end{tabular}

\section{DISC DEHYDRATION}

Table 9 below illustrates that disc dehydration which is one of the earliest features of aging and disc degeneration was present in 123 (81.45\%) patients with the most dehydrated disc seen at L4/L5 88 (71.54\%) followed by L5/S1 72 (58.53\%).

Table 9: A table showing disc dehydration

\begin{tabular}{|l|c|}
\hline VARIABLE & FREQUENCY (\%) \\
\hline Disc dehydration & $123(81.45)$ \\
\hline SITE OF LESION & $\mathrm{N}=123$ \\
\hline L1-L2 & $12(9.75)$ \\
\hline L2-L3 & $26(21.13)$ \\
\hline L3-L4 & $29(23.57)$ \\
\hline L4-L5 & $89(71.54)$ \\
\hline L5-S1 & $72(58.53)$ \\
\hline
\end{tabular}




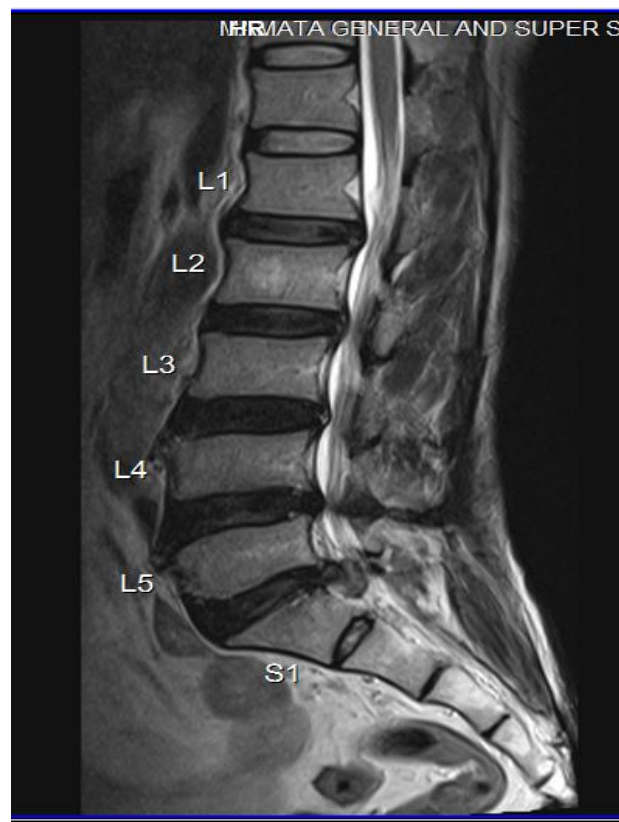

Fig.5 Sagittal mri image showing multilevel disc dehydration of lumbar spine

\section{DISCUSSION}

\section{MRI Patterns of Low Back Pain}

The current study shows different MRI patterns of lumbar spine disease patients with LBP in 151 patients who fulfilled the inclusion and exclusion criterion were included in the study during the period of july 2015 to december 2015. Symptomatic lumbar disc herniation occurs most commonly in individuals between the ages 30 and 50 years ${ }^{4}$. In our study cases are found in 3rd decade are 32 $(21.19 \%)$, cases of $4^{\text {th }}$ decade are $57(37.74 \%)$ and cases in $5^{\text {th }}$ decade are $29(19.20 \%)$. One of the risk factors is male gender ${ }^{5}$. Findings of our study showed a male to female ratio of lumbar degenerative changes are 90:61 (59.60\%:40.39\%).

Among 151 MRIs of patients presenting with LBP in this study established lumbar degenerative disc disease $(81.45 \%)$, bulges108 $(71.52 \%)$, herniations $87(57.61 \%)$, anterior osteophytes $53(35.09 \%)$,end plate changes $34(22.51 \%)$, ligamentum flavum hypertrophy $11(7.28 \%)$, facet joint arthrosis 17 (11.25\%), spondylolisthesis 3 (1.98\%), disc dehydration $123(81.45 \%)$ rest of the cases are normal $28(18.55 \%)$. The most common site for bulges and herniations was L4/L5 95 (87.96\%) and $52(59.77 \%)$. The most common complication of bulges and herniations was impingement of exiting nerve roots $41(47.12 \%)$ and compression of exiting nerve roots and cauda equina 29 (70.73\%) respectively. The most common site of anterior osteophytes, end plate changes and ligamentum flavum hypertrophy was L4/L5 24 (42.85\%), 12 $(35.2 \%)$ and $5(45.4 \%)$. Facet joint arthrosis mostly seen unilaterally and most common site of facet joint arthrosis was L5/S1 7 (41.1\%). Spondylolisthesis most common site was L5over S1 $2(66.66 \%)$.

In India, Verma et al. A retrospective study of 232 patients found the incidence of lumbar disc degeneration to be more frequent at $79.3 \%^{6}$ This study excluded spinal infections and tumors. Roy $\mathrm{SK}^{7}$ in his study found $68.57 \%$ of the patients had lumber disc herniations at the L4-L5 level, 31.42\% of the patients had lumber disc herniation at L5-S1 level. Hossain $\mathrm{MI}^{8}$ in his analysis found that distribution of intervertebral disc lesions is most common at L5-S1 level (95\%) and very closely followed by L4-5 (92\%). In our study, Lumbar disc herniation was mostly seen at L4-5 level (59.77\%) and L5-S1 level (21.83\%).

This study serves to reinforce the fact that MRI has a high sensitivity for detection of lumbar spine degenerative disease.

\section{The Common Disc Contour Abnormalities in} Patients with Low Back Pain

Different disc contour abnormalities result from LDD are referred to as either herniated or prolapsed by many physicians. ${ }^{9}$ They can further be classified as "normal, bulge and herniation; broad based protrusion, focal protrusion and extrusion. ${ }^{9}$

A disc bulge is a circumferential enlargement of the disk contour in a symmetric fashion in a weakened disk, the annulus is intact with disk extension outward involving $>50 \%$ of disk circumference or diffuse (nonfocal, non-osseous material extending beyond the normal disc space in a circumferential manner. ${ }^{10,11 .}$ A disc herniation is a localized/focal displacement of disk beyond the intervertebral disc space. ${ }^{9}$ A herniated disk can be protruded, extruded 
or sequestrated. ${ }^{9}$ A disc protrusion is a focal displacement disk material beyond the margins of adjacent vertebral endplates involving $<50 \%$ of disc circumference. An extrusion is a herniated disc in which, has a small connection with the parent disc (narrow neck). ${ }^{9}$ Many studies have been done using this classification. ${ }^{6,9,15}$

In this study the findings reported are $71.52 \%$ disc bulges and $57.61 \%$ herniations. Herniations were further reported as $62.06 \%$ broad based herniations, $4.59 \%$ extrusions and $33.33 \%$ protrusions had lesions commonly appearing at L4/L5 of which $59.77 \%$ are bulges and $87.96 \%$. On the other hand, lesions at $\mathrm{L} 5 / \mathrm{S} 1$ were seen in $21.83 \%$ and $73.14 \%$ patients with bulges and herniations respectively

Traditionally, disc degeneration is common in the areas with the heaviest mechanical stresses such as the lower lumbar region. A fact verified in this study, where the findings reported that the majority of the participants, who had bulges $(87.96 \%)$ and herniations $(59.77 \%)$, had lesions commonly appearing at L4/L5. On the other hand, lesions at L5/S1 were seen in $73.14 \%$ and $21.83 \%$ patients with bulges and herniations respectively.

\section{Lumbar Disc Degeneration common complications:}

Individuals with lumbar disc degeneration (LDD) are predisposed to the development of common potential complications such as neural compression, chemical irritation of nerves, osseous abnormalities, segmental instability, spinal stenosis and pain. ${ }^{12}$

Foraminal Narrowing is measured at the foraminal segment of the radicular canal. ${ }^{13}$

Normal Measurement: Was taken as $4 \mathrm{~mm}$. Ligamentum flavum - measured at the widest diameter on axial images.

Anteroposterior Diameter of the Spinal Canal: Measured from the posterior margin of the intervertebral disc to the spinolaminar junction.

Stenosed Spinal Canal: $<11.5 \mathrm{~mm} .^{14}$

In the study, the most common complication of bulges and herniations were reported as an impingement of exiting nerve roots $(47.12 \%)$ and compression of exiting nerve roots and cauda equine nerve roots $(70.73 \%)$ respectively. Yong et al. reported $42.1 \%$ which was slightly lower, whereas Mboka et al reported $77 \%$ nerve root compression which was comparable to the findings in this study. ${ }^{15,16 .}$

\section{Other findings of lumbar degenerative changes:}

The most common site of anterior osteophytes, end plate changes and ligamentum flavum hypertrophy was L4/L5 24 (42.85\%), 12 (35.2\%) and 5 (45.4\%). Facet joint arthrosis mostly seen unilaterally and most common site of facet joint arthrosis was L5/S1 $7(41.1 \%)$. Spondylolisthesis most common site was L5over S1-2 (66.66\%).

Anterior osteophytes tend to appear more where pressure is greatest, develop as a defense mechanism in response to pressure. In this study, it was observed that anterior osteophytes progressively increased the lower the spine level, and the most common location were L4/L5 and L5/S1.

End plate changes, ligamentum flavum hypertrophy and facet joint arthrosis occur in the process of lumbar degenerative process. Spondylolisthesis denotes anterolisthesis of one vertebra relative to the segment below and the most common site for spondylolisthesis was L5over S1 2 (66.66\%).

\section{CONCLUSION}

151 cases of low back pain were studied during the period of July 2015 to December 2015. The peak incidence was found to be in 4th decade, male female ratio was $1.47: 1$ with all the patients having the complaints of low back pain. Lumbar degenerative disc disease seen in 123 cases $(81.45 \%)$ with disc bulges 108 (71.52\%), herniations $87(57.61 \%)$ are common and the most common site for degenerative findings was L4/L5 followed by L5/S1. Nerve root compression was the most common complication. This study established the use of MRI as the radiological investigation for detection of lumbar degenerative changes of spine. 


\section{REFERENCES}

1. Lebkowski WJ, Lebkowska U, Niedzwiecka M, Dzieciol J. The radiological symptoms of lumbar disc herniation and degenerative changes of lumbar intervertebral discs. Med Sci Monit, 2004;10 (suppl 3):112-114.

2. Teasel W.R., White K. Clinical approaches to low back pain: Part 1-Epidemiology, diagnosis, and prevention. Can Fam Physician. 1994; 40:481-486.

3. Carragee, E.J. and D.H.A. Kim, 1997. Prospective Analysis of Magnetic Resonance Imaging Findings in Patients with Sciatica and Lumbar Disc Herniation. Correlation of Outcomes with Disc Fragment and Canal Morphology. Spine (Phila Pa 1976),22(14): 1650-1660.

4. Lumbar Disc Disease: The Natural History: Lumbar Disease and Low- Back Pain' Neurosurg Focus, 2002,13 (2) http:// www.medscape. com/ view article/442526.

5. Williams NS, Bulstrode CJk, O' Connell PR, Bailey and Love's Short Practice of surgery,25th edn, London: Hodder Arnold; 2008: p. 476-7.

6. Verma S.R., Gupta P.K., Munshi A., Goyal P., Verma S.C. A retrospective analysis of magnetic resonance imaging findings in 2040 year old patients with low back pain: experience at a semi-urban tertiary health care center in Northern India. The Internet Journal of Spine Surgery. 2011; 6(4): 1937 8270.

7. Roy SK, Treatment of Prolaspsed lumbar Intervetebral disc by minimally invasive open lumbar discectomy, [MS Thesis]. Dhaka: BSMMU; 2005.

8. Hossain MI, Role of MRI in Evaluation of low back pain: a study of 100 cases. [FCPS Dissertation].Dhaka: BCPS; 2003.

9. Helm, Major, Anderson, Kaplan, Dussault. Musculoskeletal MRI. 2nd edition. 2009.

10. Fardon D.F., Milette P.C. Nomenclature and classification of lumbar disc pathology.
Recommendations of the Combined task Forces of the North American Spine Society, American Society of Spine Radiology, and American Society of Neuroradiology. Spine. 2001; 26:E93-E113.

11. Grainger R.G., Allison D.J. Diagnostic Radiology. A text book of Medical Imaging. 5th edition, 2008. Chapter $60 \mathrm{html}$ version. Churchill, Livingstone, London UK.

12. Samartzis D., Karpinnen J., Chan D., Luk K.D., Cheung K.M. The association of lumbar disc degeneration on magnetic resonance imaging with body mass index, in overweight and obese adults. Arthritis Rheum. 2012 May; 64 (5): 1488-1496.

13. Boos, N., D. Dreier, E. Hilfiker, V. Schade, R. Kreis, J. Hora, M. Aebi and C. Boesch, 1997. Tissue Characterization of Symptomatic and Asymptomatic Disc Herniations by Quantitative Magnetic Resonance Imaging. Journal of Orthopaedic Res., 15(1): 141-149.

14. Albert, H.B. and C. Manniche, 2007. Modic changes following lumbar disc herniation. European Spine Journal, 16(7): 977-982.

15. Yong P.Y., Alias N.A.A., Shuaib I.L. Correlation of clinical presentation, radiography and MRI for low back pain- A preliminary survey. J HK Coll Radiol. 2003; 6: 144-151.

16. Mboka J. Pattern of spine degenerative disease among patients referred for lumbar magnetic resonance imaging at Muhimbili National Hospital Dar es Salam Tanzania March-September 2011. Mmed Radiology Dissertation. Muhimbili University of Health and Allied Sciences. May 2011. 